\title{
Efficacy of Oral Micronutrient Supplementation on Linear Nail Growth in Healthy Individuals
}

\section{-A Randomized Placebo-Controlled Double-Blind Study}

\author{
Ferial Fanian $^{1 *}\left(\mathbb{D}\right.$, Adeline Jeudy ${ }^{1,2}$, Ahmed Elkhyat ${ }^{1,2}$, Thomas Lihoreau ${ }^{1,2}$, Philippe Humbert ${ }^{1,2,3}$ \\ ${ }^{1}$ Center for Studies and Research on the Integument (CERT), Department of Dermatology, University Hospital of Besançon, \\ Besançon, France \\ ${ }^{2}$ Clinical Investigation Center (INSERM CIC 1431), Besançon University Hospital, Besançon, France \\ ${ }^{3}$ INSERM UMR1098, FED4234 IBCT, University of Franche-Comté, Besançon, France \\ Email: ^fanian@gmail.com
}

How to cite this paper: Fanian, F., Jeudy, A., Elkhyat, A., Lihoreau, T. and Humbert, P. (2020) Efficacy of Oral Micronutrient Supplementation on Linear Nail Growth in Healthy Individuals. Journal of Cosmetics, Dermatological Sciences and Applications, 10, 191-203.

https://doi.org/10.4236/jcdsa.2020.104020

Received: September 4, 2020

Accepted: December 12, 2020

Published: December 15, 2020

Copyright (c) 2020 by author(s) and Scientific Research Publishing Inc. This work is licensed under the Creative Commons Attribution International License (CC BY 4.0).

http://creativecommons.org/licenses/by/4.0/

\begin{abstract}
Introduction: Several studies demonstrate the effects of the oral supplementations on the skin while there are limited data for their effects on the nail quality in healthy individuals. Only placebo controlled double blind studies could provide the reliable data considering the physiologic nail growth. $\mathbf{O b}$ jective: The objective of this study was to evaluate the efficacy of consumption of a micronutrient supplementation on linear nail growth and thickness. Subjects and Method: 60 healthy female volunteers aged 35 to 65 years old were enrolled, randomized blindly in treatment and placebo groups, taking one tablet per day for 3 months. The evaluation was performed on D0 and D90 \pm 3 days by measuring the linear nail growth, nail thickness by high frequency ultrasound imaging and also subjects' self-assessment. Results: All 60 subjects finished the study without any serious adverse event. At D90 both groups revealed a significant linear nail growth $(5.20 \pm 0.35$ for treatment group $(\mathrm{p}=0.001)$ and $5.15 \pm 0.30$ for placebo group $(\mathrm{p}=0.001))$. However, the difference between the treatment and placebo group was statistically significant $(\mathrm{p}=0.01)$ demonstrating the efficacy of oral supplementation on linear nail growth. No significant difference was observed at D90 for nail thickness measured with HFUS between 2 groups. The self-assessment score regarding «brittle nails» and «split nails» was diminished non-significantly in both groups. Conclusion: The results observed in this trial revealed that the oral micronutrient supplementation can provide beneficial effect on nail growth. This result may be due to the whole formula as the single vitamin treatment like biotin was shown to be non-effective. A longer study would be needed to confirm the efficacy on nail thickness.
\end{abstract}




\section{Keywords}

Linear Growth, Nail Growth, Oral Supplementation

\section{Introduction}

\subsection{Nail Growth}

The nail unit is a dynamic structure which remains mitotically active throughout life [1]. Growth in the normal state occurs in a linear direction from the germinative nail matrix, with a minor contribution from the underlying nail bed [2]. The germinative layers of the nail matrix undergo DNA synthesis, divide and differentiate to produce the nail plate without a quiescent phase [3]. Kinetic studies of fingernails show an average growth rate of $0.1 \mathrm{~mm}$ per day or $3 \mathrm{~mm}$ per month $(3.47 \mathrm{~mm} / \mathrm{month}[4])$. The growth rate of toenails is approximately $60 \%$ slower, or $1 \mathrm{~mm}$ per month [3] (1.62 mm/month [4]). On average, it takes approximately 4 - 6 months for a fingernail to completely grow out and between 12 and 18 months for a toenail [5].

Orentreich et al. revealed that the rate of linear nail growth is changed among different age groups [6]. He measured the linear nail growth of 269 subjects from 10 to 100 yrs old during 12 months and he observed that: the linear nail growth increased until well into the $3 \mathrm{rd}$ decade of life. From 25 to $100 \mathrm{yr}$ of age, the rate decreased approximately $0.5 \%$ per year from an average of $0.9 \mathrm{~mm} / \mathrm{wk}$ in the $3 \mathrm{rd}$ decade. Men had a more rapid rate than women until the 6th decade. By the 8 th decade, women had a more rapid rate than men.

The longitudinal 36-yr data of Bean [7] on himself from age 32 to 68 was recalculated in millimeters per week for each year by Orentreich [6]. Studies, on a 21 -year-old individual whose day time skin temperature averaged $25^{\circ} \mathrm{C}$, showed a circadian rhythme of low growth rate of about $1 \mu \mathrm{m} / \mathrm{hr}(0.17 \mathrm{~mm} / \mathrm{wk})$ at night and a high of only $5 \mu \mathrm{m} / \mathrm{hr}(0.84 \mathrm{~mm} / \mathrm{wk})$ in the daytime (Figure 1) [6].

Regarding the effect of human temperature on linear nail growth, several studies showed a low growth rate of $0.5 \mu \mathrm{m} / \mathrm{h}(0.08 \mathrm{~mm} / \mathrm{wk})$ of nail growth at $16^{\circ} \mathrm{C}$ and a high rate of $12 \mu \mathrm{m} / \mathrm{hr}(2.0 \mathrm{~mm} / \mathrm{wk})$ at $32^{\circ} \mathrm{C}[6]$.

There is strong evidence that many factors can modify nail growth including hormones (e.g., thyroid, pregnancy), medications (e.g., methotrexate, azathioprine), diet (e.g., poor nutrition), and environmental factors (e.g., ambient outdoor temperature) [8].

Regarding the effect of nutritional status on linear nail growth, Gilchrist showed on 379 school students that although there is a considerable individual variation in nail growth, the nails of poorly nourished children grew more slowly [9]. The evidence suggests that the nail growth of well-nourished children shows less variation than that of the more poorly nourished.

The role of the ABO blood group on nail growth has been shown by Qadir MI on 172 subjects: the fastest nail growth was observed in B-females and slowest in 


\section{A-males [10].}

In the study of Abraham et al. [11], the average rate of nail growth was 0.113 $\mathrm{mm} /$ day. The rate of nail growth was found to be more in females, younger individuals, pregnancy, patients on nutritional supplementation and psoriasis.

\subsection{Nail Growth Measurements}

Nail evaluations have been documented in the literature as early as 1684 . However, the modern day measuring technique dates back to 1939 by Gilchrist and Buxton in their pivotal study of nail growth [9]. They utilized a fixed groove in the nail compared to another reference point and then measured the change over a set period of time. Subsequent studies remained similar to this original technique, although with some modifications to reference points, and use of magnification and photography to increase accuracy [12].

In 1953, Bean published on a 10 year study of the growth of his left thumb nail. He commented in this paper, referring to previous work on the subject, that nail measurements could be made in three different ways. First, marking the nail with an indelible stain such as nitric acid; second, scoring the nail with a sharp instrument; and third, weighing or measuring clippings from the nail [12]. In 1963, Bean published a twenty year study of his own nail growth, which was a continuation of his previous studies. He modified his original technique from the ten year study with a tattoo on the proximal nail fold adjacent to the cuticle as a reference point. He tattooed his skin to make a permanent reference mark in the case that his cuticle advanced or receded [13]. He also started to use magnified photographs. He used the same technique for his 25 years study on his left thumbnail [14].

Table 1 summarized the details of various publications on linear nail growth [12].

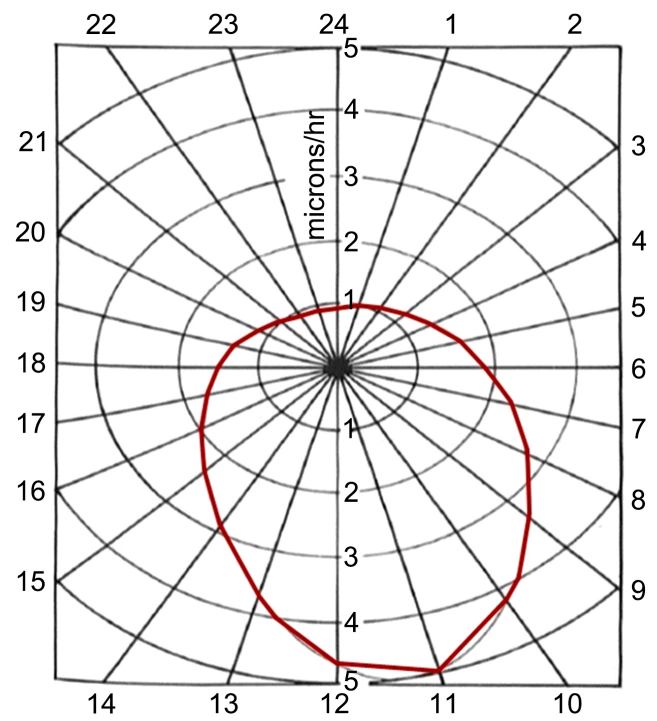

Figure 1. Human linear nail growth rate: circadial study of a 21-yr-old done by Orentreich, 1979. 
Table 1. Summary of nail growth measurement methods, Lipner and Scher, Agache's Measuring the Skin, 2017 [12].

\begin{tabular}{|c|c|c|}
\hline Authors & Reference Point & Notes \\
\hline $\begin{array}{l}\text { Gilchrist and Buxton, } \\
1939[7]\end{array}$ & $\begin{array}{l}2 \mathrm{~mm} \text { from distal } \\
\text { point of lunula }\end{array}$ & $\begin{array}{c}\text { Lunula not clear in } 4^{\text {th }} \text { and } 5^{\text {th }} \text { fingers, } \\
\text { blurred with magnification }\end{array}$ \\
\hline Bean, 1953 [9] & Cuticle & $\begin{array}{l}\text { Cuticle may be damaged due to hydra- } \\
\text { tion, dehydration, friction, manicuring. } \\
\text { May be hard to see or absent in } \\
\text { some individuals }\end{array}$ \\
\hline Hillman, 1955 [10] & Convexmargin of lunula & Used calipers to increase accuracy \\
\hline Babcock, 1955 [11] & Lunula & Magnified photographs $6.4 \mathrm{x}$ \\
\hline Sibinga, 1959 [12] & Lunula & Magnified photographs $35 \mathrm{x}$ \\
\hline Geoghegan et al., 1958 [13] & Lunula & Beck Luminex magnifier \\
\hline Morton, $1962[14]$ & Lunula & Drilled holes, magnified photographs \\
\hline Bean, 1963 [15] & $\begin{array}{l}\text { Tattoo on proximal nail fold } \\
\text { adjacent to cuticle }\end{array}$ & Magnified photographs \\
\hline Dawber, 1970 [17] & $3 \mathrm{~mm}$ from cuticle & $8 \mathrm{x}$ magnifier \\
\hline Orentreich, 1979 [19] & Convex margin of lunula & Magnifier \\
\hline
\end{tabular}

\subsection{Nail Thickness Measurements}

Nail thickness can easily be measured at the free edge of the nail but there may be variability in thickness across the nail plate [15]. Also, distal nail thickness takes many months to reflect changes resulting from changes in proximal nail growth. A non-invasive technique is, therefore, needed to measure thickness across the nail plate in vivo. High Frequency Ultrasound imaging (HFUS) would be an obvious choice as there is a clear boundary of tissue density between the nail and the underlying nail bed [15] [16]. Finlay et al. observed a clear rank order of distal and proximal nail transmission times: thumb $>$ index $>$ middle $>$ ring $>$ little fingers [15]. They showed later in 1990 that the right thumb distal micrometer readings in the males $(0.59 \mathrm{~mm} \pm 0.09)$ are thicker than those in the females $(0.49 \mathrm{~mm} \pm 0.07)(\mathrm{n}=10, \mathrm{P}<0.001$, Wilcoxon signed ranks test $)$ [17]. In the study of Wollina et al. [16] the nail thickness varied between $0.481 \mathrm{~mm}$ (right thumb) and $0.397 \mathrm{~mm}$ (left fifth finger).

Mogensen et al. concluded in their study comparing OCT and HFUS that the nail structures can be imaged by both techniques but because OCT has higher resolution than HFUS, it has an ability to discriminate subtle changes not detected by ultrasound, and thus provide more information about the nail unit [18]. The OCT imaging is able also to visualize the lunula and leuconychia clearly because of increased reflection backscattering of these areas. Later in 2017, Berrito et al. suggested that using the Ultra HFUS with $48-70 \mathrm{MHz}$ and the resolution of $30 \mu \mathrm{m}$, could permit new diagnostic applications to small parts such as nails [19]. 


\subsection{Nail Growth and Supplementations}

Nowadays, there are many studies which revealed the effect of oral supplementations on the skin quality [20]-[30] while there are few published studies on the effect of an oral supplementation on nails growth and quality. The majority of available data are on the pathologic conditions like Brittle nail syndrome, yellow nail syndrome, onychoschizia, etc. A review on the effect of Biotin on skin, hair and nail concluded that research demonstrating the efficacy of oral biotin supplementation alone on healthy individuals is limited while in cases of acquired and inherited causes of biotin deficiency as well as pathologies, such as brittle nail syndrome or uncombable hair, biotin supplementation may be of benefit [31].

Abraham et al. observed a higher rate of nail, growth in the subjects under supplementation [11].

Hexsel et al. verified the effect of a bioactive collagen peptides (BCP, VERISOL) $2.5 \mathrm{~g}$ once daily for 24 weeks followed by a 4 -week off-therapy period on 25 participants with brittle nails [32]. This oral supplementation promoted an increase of $12 \%$ nail growth rate and a decrease of $42 \%$ in the frequency of broken nails. Additionally, $64 \%$ of participants achieved a global clinical improvement in brittle nails, and $88 \%$ of participants experienced an improvement 4 weeks post-treatment. The majority of participants $(80 \%)$ agreed that the use of BCP improved their nails' appearance, and were completely satisfied with the performance of the treatment [32].

Considering the remarkable lack of evidence based data in this field, we decided to run a randomized placebo controlled clinical trial to evaluate the effect of an oral supplementation, specific for skin, hair and nails on the linear nail growth in healthy individuals.

\section{Subjects and Methods}

This is a monocenter randomized placebo controlled double blind study on 60 healthy female subjects of 35 to 65 yrs old who pledged not to use any other similar product during the whole duration of the study and who accepted to have a small tattoo on her nail. The subjects have been enrolled in this study by signing a written informed consent. The study ran at Center for Study and Research on the Tegument (CERT) situated at department of Dermatology of University Hospital of Besançon, France respecting IHC-GCP with all needful authorizations taken from the ethical committee and French National authority for Health (ANSM) with the authorization number of 2016-A00053-48.

As the objectives of the study was to evaluate the effect of the supplementation on the healthy volunteers without any nail problem, the inclusion criteria were the female volunteers of 35 - 65 years, non-smoking or smoking no more than 5 pack-years, who pledge not to use any other similar product during the whole duration of the study, who accept to have a small tattoo on her nail, who have a fixed address and entitled to Social Security or a similar National Insurance 
Scheme and who sign a written informed consent.

The non-inclusion criteria were having used cosmetics and/or topical preparations containing ingredients claiming efficacy on nail quality or growth or any other oral supplementation less than 3 month before and/or during the study, participating in a trial simultaneously or are in the exclusion period following their participation in another study, pregnant, nursing, or intending to become pregnant in the course of the study, with a history of allergy or hypersensitivity to this product or one of their components, with a dermatosis, systemic disease or treatment susceptible to interfere with the evolution of the parameters of the study.

The subjects were evaluated at D0 and D90 \pm 3 days by measuring the linear nail growth and nail thickness as well.

The product assignment was randomized. Table randomization by blocks was performed by CERT. Each subject was randomly assigned to a treatment or placebo, according to a central randomization table generated using a computer program. The product was allocated to each volunteer according to the inclusion order. The subjects took 1 tablet of Perfectil ${ }^{\otimes}$ Original (VITABIOTICS Ltd, London, UK) per day for 3 months. The composition of the product is shown in Table 2.

\subsection{Evaluation Methods}

\subsubsection{Measurement Conditions}

The measurements were performed in controlled conditions regarding the temperature $\left(22^{\circ} \mathrm{C} \pm 2{ }^{\circ} \mathrm{C}\right)$ and hygrometry $(50 \% \pm 10 \%)$. The subjects remained in the mentioned condition at least 15 minutes before measures.

\subsubsection{Linear Nail Growth Measurement}

The linear nail growth was measured according to the published method: the distance between a micro-tattoo mark on the nail and the cuticle has been measured at D0 and D90 in both groups. The mark was made on the middle finger, on bottom of the nail by a micro-tattoo. The mark was performed cautiously to prevent overheating of the nail and to avoid complete perforation of the nail and damage to the underlying nail bed (Figure 2). The distance between the proximal nail fold has been measured blindly by a technician via a caliper at D0 nd D90. The measures recorded in the CRF of the subjects.

\subsubsection{Nail Thickness Measurement by High Frequency Ultrasound}

Cutaneous ultrasound imaging is a technique allowing the in vivo visualization of the structure of the different skin layers. An ultrasonic wave is applied to the surface of the skin by means of a suitable probe. The echogenicity of the different layers depends on their nature:

- Low echogenicity is displayed by water-rich structures (or inflamed tissue for example) or by low fibril containing tissue (upper dermis).

- High echogenicity is displayed by fibrous tissue such as the collagen-rich dermal matrix. 
Table 2. Nutritional information of Perfectil ${ }^{\varpi}$ Original (VITABIOTICS Ltd, London, UK).

\begin{tabular}{|c|c|c|}
\hline Nutritional Information & Average per tablet & $\% \mathrm{EC} \mathrm{NRV}^{*}$ \\
\hline Vitamin D (D3 200 IU) & $5 \mu \mathrm{g}$ & 100 \\
\hline Vitamin E (Natural Source) & $40 \mathrm{mg}$ a-TE & 333 \\
\hline Vitamin C & $60 \mathrm{mg}$ & 75 \\
\hline Thiamin (Vit. B1) & $8 \mathrm{mg}$ & 727 \\
\hline Riboflavin (Vit. B2) & $4 \mathrm{mg}$ & 286 \\
\hline Niacin (Vit. B3) & $18 \mathrm{mg} \mathrm{NE}$ & 113 \\
\hline Vitamin B6 & $10 \mathrm{mg}$ & 714 \\
\hline Folic Acid & $400 \mu \mathrm{g}$ & 200 \\
\hline Vitamin B12 & $9 \mu \mathrm{g}$ & 360 \\
\hline Biotin & $45 \mu \mathrm{g}$ & 90 \\
\hline Pantothenic Acid & $40 \mathrm{mg}$ & 667 \\
\hline Magnesium & $75 \mathrm{mg}$ & 20 \\
\hline Iron & $12 \mathrm{mg}$ & 86 \\
\hline Zinc & $15 \mathrm{mg}$ & 150 \\
\hline Copper & $1000 \mu \mathrm{g}$ & 100 \\
\hline Manganese & $0.5 \mathrm{mg}$ & 25 \\
\hline Selenium & $100 \mu \mathrm{g}$ & 182 \\
\hline Chromium GTF & $50 \mu \mathrm{g}$ & 125 \\
\hline Iodine & $200 \mu \mathrm{g}$ & 133 \\
\hline L-Cysteine & $10 \mathrm{mg}$ & -- \\
\hline Betacarotene & $2 \mathrm{mg}$ & -- \\
\hline GrapeSeedExtract (95\% proanthocyanidins) & $15 \mathrm{mg}$ & -- \\
\hline
\end{tabular}

${ }^{*} \mathrm{NRV}=$ Nutrient Reference Value, $\mu \mathrm{g}=$ microgram, $\mathrm{mg}=$ milligram, $\mathrm{IU}=$ International Units.

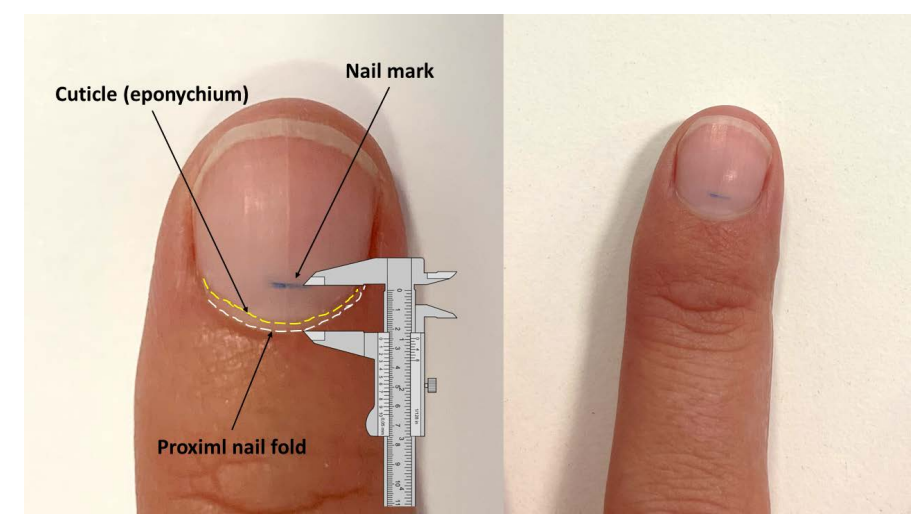

Figure 2. Nail mark was performed delicately with a sharp object and a blue ink was tattooed to the mark. The distance between the proximl nail fold and the marked line was measured at $\mathrm{T} 0$ and $\mathrm{T} 3$ months. 
A longitudinal scanning of the skin surface provides a cross-section of the skin. The analysis was achieved to obtain the thickness of the nail by $20 \mathrm{MHz}$ probe (Dermcup ${ }^{\circledast}$ Atys, France). At least 3 acquisitions were performed on the nail. Nail thickness was assessed on 3 parts of each image (9 values for each nail in each session) (Figure 3).

\subsubsection{Subject Self-Assessment}

The subjects answered the following questions at D0 and D90:

- Are your nails brittle? $(0=$ not $\rightarrow 10=$ very $)$

- Are your nails split? $(0=$ not $\rightarrow 10=$ very $)$

\subsection{Statistical Analysis}

Statistical comparisons of basal values, of evolutions between assessments (Student or Mann Whitney depending of the normality of the distribution) and on the delta was carried out with the Anova or Mann Whitney test (depending on the normality of the distribution). The analyses were carried out with Statistical Version 7.1 and Graphpad Instat Version 3.06.

\section{Results}

\subsection{Study Population}

60 volunteers were enrolled. They have been randomized to two homogenized groups upon the age, ethnicity, lifestyle and diet. No subject was stopped prematurely. To be included in the analysis ITT, the subjects had to complete the study. So, the analysis is carried out on two groups of 30 subjects.

Sixty (60) healthy Caucasian female volunteers aged 35 to 65 years (mean $48 \pm$ 5 years, mean active group 48.6, mean placebo group 48.9) were enrolled (Table 3). No subject was stopped prematurely. $55 \%$ of active group and $46 \%$ of placebo group were menopaused. No differences were observed in terms of diet between both groups. No modification was recorded for diet and lifestyle of the subjects during the study.
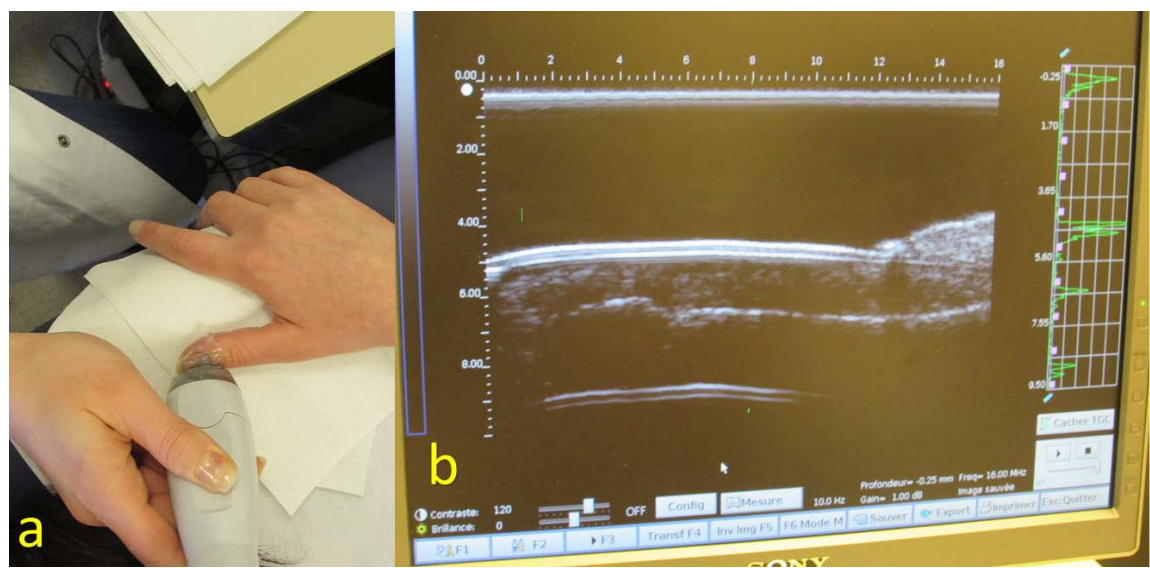

Figure 3. The High Frequency Ultrasound imaging system (Dermcup, Atys, France) measuring the nail thickness on thumb (a). 3 measures performed on each image (b). 
Table 3. Subjects demographic data.

\begin{tabular}{ccc}
\hline & \multicolumn{2}{c}{ Test group } \\
\cline { 2 - 3 } Parameters & $\begin{array}{c}\text { Active group } \\
(n=30)\end{array}$ & $\begin{array}{c}\text { Placebo Group } \\
(n=30)\end{array}$ \\
\hline Average age, years & $48.6 \pm 5.1$ & $48.9 \pm 5.6$ \\
Menopause & $17(56 \%)$ & $14(46 \%)$ \\
Diet & & $2(6.6 \%)$ \\
Vegetarian & $3(10 \%)$ & $4(13.4 \%)$ \\
Low calory & $5(16 \%)$ & $24(80 \%)$ \\
Normal & $22(74 \%)$ &
\end{tabular}

\subsection{Main Criterion}

\section{Linear Nail Growth}

At D0, the distance between the nail mark and Cuticle among both groups were almost equal (4.16 \pm 0.39 in treatment group and $4.15 \pm 0.22$ in placebo group). At D90 both groups revealed a significant linear nail growth $(5.23 \pm 0.30$ for treatment group (25.7\%), p $=0.001$ and $5.05 \pm 0.30$ for placebo group (21.6\%), p $=0.001)$. However, the difference between the treatment and placebo group was significant $(\mathrm{p}=0.01)$ demonstrating the significant efficacy of oral supplementation on linear nail growth (Figure 4).

\subsection{Secondary Criteria}

\subsubsection{Nail thickness by High frequency Ultrasound}

At D0, the nail thickness among both groups was equal $(0.43 \pm 0.4$ in treatment group and $0.43 \pm 0.5$ in placebo group). At D90 no significant evolution was recorded neither for treatment nor placebo group $(0.43 \pm 0.5$ in treatment group and $0.43 \pm 0.4$ in placebo group). No significant difference between the treatment and placebo group at $\mathrm{D} 90$ were observed.

\subsubsection{Subjects Self-Assessments}

The score of the question regarding «brittle nails» and also «split nails» was diminished non-significantly in both group.

\section{Discussion}

This study took place at the CERT located within the Department of Dermatology, University Hospital of Besançon, France between December and April. 60 healthy female volunteers without any nail pathology participated in this randomized double-blind comparative study, aimed to investigate the effects of Perfectil Original tablet on nails growth and thickness. The products were taken during 3 months and the volunteers were examined at D0 (before treatment) and at D90 (3 months). All measurements took place in a temperature- and humidity-regulated environment. The volunteers sat quietly at least 15 minutes in stable environmental conditions before measurements were conducted. 


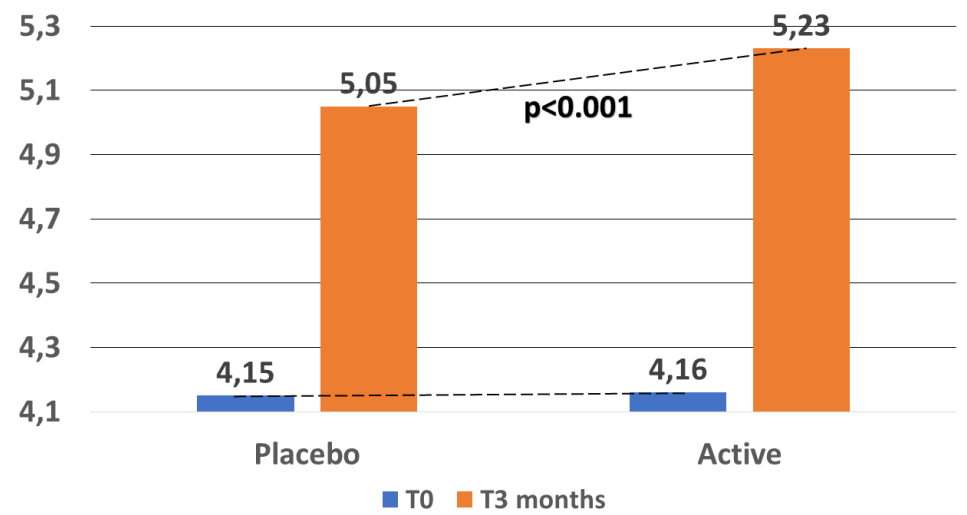

Figure 4. Distance between Proximal nail fold and marked line ( $\mathrm{mm})$ by time at T0 and T3 months: The time effect in both groups is significative while the difference between active and placebo group is significative too $(\mathrm{p}<0.001)$ showing the efficacy of the supplementation.

The methods used in this trial are similar to published methods previously tested by different researchers [3] [4] [6]-[12] [32] [33]. As mentioned before, there are a few published articles on the effects of an oral supplementation on nail growth. In addition, the majority of them evaluate the nail growth in only one group without any control. According to the results obtained from the present study, the linear nail growth is significant even in placebo group because the study population is healthy with normal nail growth. Therefore, in order to demonstrate the efficacy of an oral treatment, the study should be a controlled one where the difference between two groups is significant. For the topical treatments, it is highly recommended to design the split body studies.

High frequency ultrasound imaging at $20 \mathrm{MHz}$ was recommended by several publications [15] [16] [18] [34]. Although Berritto suggested an Ultra HFUS with $48-70 \mathrm{MHz}$ for evaluation the nail plate, the majority of publication concluded that the $20 \mathrm{MHz}$ is suitable.

The study limitations were duration of the study which limited the precise judgment of the nail thickness. Unfortunately all of these studies contain the cross sectional data and there is no evidence to clarify the duration of treatment to be enough to modify the nail thickness. As our study duration was 3 months, we think that we need more time to observe this modification because we need a total nail shedding to measure the new nail thickness. On the other hand, we may conclude that the oral supplementation on healthy individuals may stimulate only the nail growth and not its thickness as this parameter is already normal in the healthy volunteers.

\section{Conclusion}

The results observed in this trial suggest that the oral micronutrient supplementation can provide beneficial effect on nail growth. This result may be due to the whole formula as the single treatment like biotin alone was shown to be 
non-effective [31]. A longer study is needed to confirm the efficacy on nail thickness as well. Although one study suggested an Ultra HFUS with $48-70$ $\mathrm{MHz}$ for evaluating the nail plate, the majority of the publications concluded that the $20 \mathrm{MHz}$ is suitable for anatomical evaluation of nail plate in clinical trials.

\section{Acknowledgements}

Authors keep the memory of Dr Ahmed Elkhyat who has participated very actively in all steps of this scientific project from concept to the manuscript final revision but unfortunately, he passed away before publishing this article.

This research paper is made possible through the help and support from everyone, including: patients, technicians and research engineers of our center, especially Mrs Celine THIEBAUD, Mrs Aurelie DURAI and Mrs Vanessa ECARNOT for their appreciable enthusiasm to carry out the exact measures.

\section{Conflicts of Interest}

The authors declare no conflict of interest. The study was commissioned by Vitabiotics Ltd. company.

\section{References}

[1] Baran, R. (2002) The New Oral Antifungal Drugs in the Treatment of the Yellow Nail Syndrome. British Journal of Dermatology, 147, 180-195. https://doi.org/10.1046/j.1365-2133.2002.48119.x

[2] Johnson, M., Comaish, J.S. and Shuster, S. (1991) Nail Is Produced by the Normal Nail Bed: A Controversy Resolved. British Journal of Dermatology, 125, 27-29. https://doi.org/10.1111/j.1365-2133.1991.tb06034.x

[3] Hillman, R.W. (1955) Fingernail Growth in the Human Subject; Rates and Variations in 300 Individuals. Human Biology, 27, 274-283.

[4] Yaemsiri, S., Hou, N., Slining, M.M. and He, K. (2010) Growth Rate of Human Fingernails and Toenails in Healthy American Young Adults. Journal of the European Academy of Dermatology and Venereology, 24, 420-423. https://doi.org/10.1111/j.1468-3083.2009.03426.x

[5] Cohen, P.R. and Scher, R.K. (1992) Geriatric Nail Disorders: Diagnosis and Treatment. Journal of the American Academy of Dermatology, 26, 521-531. https://doi.org/10.1016/0190-9622(92)70075-Q

[6] Orentreich, N., Markofsky, J. and Vogelman, J.H. (1979) The Effect of Aging on the Rate of Linear Nail Growth. Journal of Investigative Dermatology, 73, 126-130. https://doi.org/10.1111/1523-1747.ep12532799

[7] Bean, W.B. (1974) Nail Growth: 30 Years of Observation. Archives of Internal Medicine, 134, 497-502. https://doi.org/10.1001/archinte.1974.00320210107015

[8] Dawber, R. and Baran, R. (1987) Nail Growth. Cutis, 39, 99-103.

[9] Gilchrist, M.L. (1939) The Relation of Finger-Nail Growth to Nutritional Status. Journal of Anatomy, 73, 575-582.

[10] Qadir, M.I. and Sana, Z. (2019) Role of Blood Group in Nail Growth. Asian Journal of Applied Science and Technology, 3, 78-81. 
[11] Abraham, A., Roga, G. and Thomas, N. (2015) A Pilot Study: Nailing Indian Elections with the Indelible Ink Mark. Indian Journal of Dermatology, 60, 562-565. https://doi.org/10.4103/0019-5154.169126

[12] Lipner, S.R. and Scher, R. (2017) Nail Growth Evaluation and Factors Affecting Nail Growth. In: Humbert, P., Fanian, F., Maibach, H.I. and Agache, P., Eds., Agache's Measuring the Skin, Springer, Cham, 867-881. https://doi.org/10.1007/978-3-319-32383-1_121

[13] Bean, W.B. (1963) Nail Growth. A Twenty-Year Study. Archives of Internal Medicine, 111, 476-482. https://doi.org/10.1001/archinte.1963.03620280076012

[14] Bean, W.B. (1968) Nail Growth. Tweny-Five Years' Observation. Archives of Internal Medicine, 122, 359-361. https://doi.org/10.1001/archinte.1968.00300090069016

[15] Finlay, A.Y., Moseley, H. and Duggan, T.C. (1987) Ultrasound Transmission Time: An in Vivo Guide to Nail Thickness. British Journal of Dermatology, 117, 765-770. https://doi.org/10.1111/j.1365-2133.1987.tb07358.x

[16] Wollina, U., Berger, M. and Karte, K. (2001) Calculation of Nail Plate and Nail Matrix Parameters by $20 \mathrm{MHz}$ Ultrasound in Healthy Volunteers and Patients with Skin Disease. Skin Research and Technology, 7, 60-64. https://doi.org/10.1034/j.1600-0846.2001.007001060.x

[17] Finlay, A.Y., Western, B. and Edwards, C. (1990) Ultrasound Velocity in Human Fingernail and Effects of Hydration: Validation of in Vivo Nail Thickness Measurement Techniques. British Journal of Dermatology, 123, 365-373.

https://doi.org/10.1111/j.1365-2133.1990.tb06297.x

[18] Mogensen, M., Thomsen, J.B., Skovgaard, L.T. and Jemec, G.B.E. (2007) Nail Thickness Measurements Using Optical Coherence Tomography and 20-MHz Ultrasonography. British Journal of Dermatology, 157, 894-900. https://doi.org/10.1111/j.1365-2133.2007.08118.x

[19] Berritto, D., Iacobellis, F., Rossi, C., Reginelli, A., Cappabianca, S. and Grassi, R. (2017) Ultra High-Frequency Ultrasound: New Capabilities for Nail Anatomy Exploration. The Journal of Dermatology, 44, 43-46. https://doi.org/10.1111/1346-8138.13495

[20] Primavera, G. and Berardesca, E. (2005) Clinical and Instrumental Evaluation of a Food Supplement in Improving Skin Hydration. International Journal of Cosmetic Science, 27, 199-204. https://doi.org/10.1111/j.1467-2494.2005.00237.x

[21] Czajka, A., Kania, E.M., Genovese, L., Corbo, A., Merone, G., Luci, C., et al. (2018) Daily Oral Supplementation with Collagen Peptides Combined with Vitamins and Other Bioactive Compounds Improves Skin Elasticity and Has a Beneficial Effect on Joint and General Wellbeing. Nutrition Research, 57, 97-108. https://doi.org/10.1016/j.nutres.2018.06.001

[22] Fanian, F., Mac-Mary, S., Jeudy, A., Lihoreau, T., Messikh, R., Ortonne, J.-P., et al. (2013) Efficacy of Micronutrient Supplementation on Skin Aging and Seasonal Variation: A Randomized, Placebo-Controlled, Double-Blind Study. Clinical Interventions in Aging, 8, 1527-1537. https://doi.org/10.2147/CIA.S43976

[23] Higurashi, S., Haruta-Ono, Y., Urazono, H., Kobayashi, T. and Kadooka, Y. (2015) Improvement of Skin Condition by Oral Supplementation with Sphingomyelin-Containing Milk Phospholipids in a Double-Blind, Placebo-Controlled, Randomized Trial. Journal of Dairy Science, 98, 6706-6712. https://doi.org/10.3168/jds.2015-9529

[24] Shimizu, J., Asami, N., Kataoka, A., Sugihara, F., Inoue, N., Kimira, Y., Wada, M. and Mano, H. (2015) Oral Collagen-Derived Dipeptides, Prolyl-Hydroxyproline 
and Hydroxyprolyl-Glycine, Ameliorate Skin Barrier Dysfunction and Alter Gene Expression Profiles in the Skin. Biochemical and Biophysical Research Communications, 456, 626-630. https://doi.org/10.1016/j.bbrc.2014.12.006

[25] Proksch, E., Segger, D., Degwert, J., Schunck, M., Zague, V. and Oesser, S. (2014) Oral Supplementation of Specific Collagen Peptides Has Beneficial Effects on Human Skin Physiology: A Double-Blind, Placebo-Controlled Study. Skin Pharmacology and Physiology, 27, 47-55. https://doi.org/10.1159/000351376

[26] Kim, J.-E., Song, D., Kim, J., Choi, J., Kim, J.R., Yoon, H.-S., et al. (2016) Oral Supplementation with Cocoa Extract Reduces UVB-Induced Wrinkles in Hairless Mouse Skin. Journal of Investigative Dermatology, 136, 1012-1021. https://doi.org/10.1016/j.jid.2015.11.032

[27] Juturu, V., Bowman, J.P. and Deshpande, J. (2016) Overall Skin Tone and Skin-Lightening-Improving Effects with Oral Supplementation of Lutein and Zeaxanthin Isomers: A Double-Blind, Placebo-Controlled Clinical Trial. Clinical, Cosmetic and Investigational Dermatology, 9, 325-332. https://doi.org/10.2147/CCID.S115519

[28] Babizhayev, M.A., Deyev, A.I., Savel'yeva, E.L., Lankin, V.Z. and Yegorov, Y.E. (2012) Skin Beautification with Oral Non-Hydrolized Versions of Carnosine and Carcinine: Effective Therapeutic Management and Cosmetic Skincare Solutions against Oxidative Glycation and Free-Radical Production as a Causal Mechanism of Diabetic Complications and Skin Aging. Journal of Dermatological Treatment, 23, 345-384. https://doi.org/10.3109/09546634.2010.521812

[29] Asserin, J., Lati, E., Shioya, T. and Prawitt, J. (2015) The Effect of Oral Collagen Peptide Supplementation on Skin Moisture and the Dermal Collagen Network: Evidence from an ex Vivo Model and Randomized, Placebo-Controlled Clinical Trials. Journal of Cosmetic Dermatology, 14, 291-301.

https://doi.org/10.1111/jocd.12174

[30] Maia Campos, P.M.B.G., Melo, M.O. and Siqueira César, F.C. (2019) Topical Application and Oral Supplementation of Peptides in the Improvement of Skin Viscoelasticity and Density. Journal of Cosmetic Dermatology, 18, 1693-1699.

https://doi.org/10.1111/jocd.12893

[31] Patel, D.P., Swink, S.M. and Castelo-Soccio, L. (2017) A Review of the Use of Biotin for Hair Loss. Skin Appendage Disorders, 3, 166-169.

https://doi.org/10.1159/000462981

[32] Hexsel, D., Zague, V., Schunck, M., Siega, C., Camozzato, F.O. and Oesser, S. (2017) Oral Supplementation with Specific Bioactive Collagen Peptides Improves Nail Growth and Reduces Symptoms of Brittle Nails. Journal of Cosmetic Dermatology, 16, 520-526. https://doi.org/10.1111/jocd.12393

[33] Griffiths, W.A. and Reshad, H. (1983) Hair and Nail Growth: An Investigation of the Role of Left- and Right-Handedness. Clinical and Experimental Dermatology, 8, 129-133. https://doi.org/10.1111/j.1365-2230.1983.tb01756.x

[34] Jemec, G.B. and Serup, J. (1989) Ultrasound Structure of the Human Nail Plate. Archives of Dermatology, 125, 643-646. https://doi.org/10.1001/archderm.1989.01670170057008 